\title{
Actions of Dopamine on Prefrontal Neurons from Methamphetamine-Pretreated Rats
}

\author{
HIDEKI YANO, HIDEHO HIGASHI AND SYOGORO NISHI* \\ Department of Physiology and *Institute of Brain Diseases, \\ Kurume University School of Medicine, Kurume, 830 Japan
}

Received for publication on October 15, 1991

\begin{abstract}
Key words: dopamine - dopamine receptor subtypes - methamphetamine - prefrontal neurons - nucleus accumbens
\end{abstract}

We have reported previously that neurons in the nucleus accumbens, which is one of the major structures receiving the mesolimbic dopaminergic fibers, are endowed with the dopamine $\mathrm{D}_{1}$ and $\mathrm{D}_{2}$ receptors (Uchimura et al. 1986; Higashi et al. 1989). Activation by dopamine of the $\mathrm{D}_{1}$ receptor produces a hyperpolarizing response while that of the $\mathrm{D}_{2}$ receptor elicits a depolarizing response (Uchimura et al. 1986; Higashi et al. 1989). We have also reported that the accumbens neurons of the rats pretreated with methamphetamine are approximately 100 times more sensitive than control neurons to the hyperpolarizing action of dopamine and only $1 / 10$ th as sensitive to the depolarizing action of dopamine. (Higashi et al. 1989). Our recent study revealed that the prefrontal neurons which receive, similarly to the accumbens neurons, the dopaminergic fibers from the A-10 area are also endowed with $D_{1}$ and $D_{2}$ receptors, activation of which by dopamine produces hyperpolarization and depolarization, respectively (Yano et al. 1989). This is quite different from the nigral neurons which are dopaminergic and endowed with $\mathrm{D}_{2}$ receptors only, and activation of these receptors generates hyperpolarization instead of depolarization (Lacey et al. 1988). The present study was under- taken to clarify what sort of changes might occur in the $D_{1}$ and $D_{2}$ receptors on prefrontal neurons following pretreatment of the rats with methamphetamine.

Male Wistar rats, weighing $300-350 \mathrm{~g}$, were used in all the experiments. Each experimental rat received an intraperitoneal injection of methamphetamine hydrochloride $(6 \mathrm{mg} / \mathrm{kg})$ in the home cage, every 3 days, for a total of seven injections. After the drug period, they were kept for a week without the drug. Con trol rats were injected with saline, according to the same schedule as the methamphetamine rats. The stereotyped behavior was scored, every $10 \mathrm{~min}$ for 60 $\mathrm{min}$, after the administration of $2 \mathrm{mg} / \mathrm{kg}$ methamphetamine to saline- and methamphetamine-pretreated rats (Creese and Iversen, 1973). In all the rats, the stereotyped behavior and locomotion were augmented by the repeated intermittent methamphetamine pretreatment. The rats were maintained on a drug-free protocol for 24-36 $\mathrm{h}$ and were then killed under light ether anesthesia. The forebrain was quickly removed and sliced frontally by a vibratome (Oxford) at about $400 \mu \mathrm{m}$ intervals. A fresh slice of the prefrontal region was transferred to a recording chamber and completely submerged in a continuously flowing Krebs solution $\left(37^{\circ} \mathrm{C}\right)$ 
gassed with $95 \% \mathrm{O}_{2}-5 \% \mathrm{CO}_{2}$ (Uchimura et al. 1986). Intracellular recordings were obtained from neurons in and near the Vth layer of the medial prefrontal cortex. Recording electrodes were $3 \mathrm{M} \mathrm{K}$-acetatefilled glass micro-pipettes with tip resistances of 40 to $80 \mathrm{M} \Omega$, and connected to a high-input-impedance preamplifier (WPI M701). All drugs were applied to the tissue by superfusion. This study was based on more than 60 neurons in brain slices from 10 control and 10 methamphetamine-treated rats.

In both slices from control and methamphetamine-pretreated rats, the amplitudes of the dopamine hyperpolarizations were enhanced as the concentration of dopamine was increased. Moreover, dopamine at the higher concentrations produced a biphasic response - a hyperpolarization followed by a long depolarization. The hyperpolarizing response was selectively blocked by a $D_{1}$ receptor antagonist SCH-23390 $(1 \mu \mathrm{M})$ and the depolarizing response by a $D_{2}$ receptor antagonist piquindone $(3 \mu \mathrm{M})$. The minimal concentrations for producing the dopamine hyperpolarization were approximately $0.1 \mu \mathrm{M}$ and $0.003 \mu \mathrm{M}$ in control and methamphetamine-pretreated neurons, respectively. On the other hand, the minimal doses for inducing the dopamine depolarization were approximately $0.3 \mu \mathrm{M}$ and $3 \mu \mathrm{M}$ in control and methamphetamine-pretreated neurons, respectively. The results demonstrated that the dose-response relationship for the dopamine hyperpolarization was shifted to the left in parallel fashion by the methamphetamine pretreatment. Approximately $1 / 30$ th the concentration of dopamine was required to produce the same hyperpolarizing response in methamphetamine-pretreated neurons as in control neurons. Conversely, the curve for the dopamine depolarization was shifted to the right by the methamphetamine pretreatment, and about 10 times high oconcentrations of dopamine were necessary to generate equivalent responses in methamphetamine pretreated neurons.

The present study demonstrates that the methamphetamine-induced alterations in the activities of $D_{1}$ and $D_{2}$ receptors on the prefrontal neurons were quite similar to those on the accumbens neurons, i. e., an increase in the $D_{1}$ receptor activity and a decrease in the $D_{2}$ receptor activity, although the former was much greater in the accumbens neurons (Higashi et al. 1989). It seems reasonable to conclude, therefore, that methamphetamine pretreatment causes in a given dopamine receptor subtype quite a similar, if not identical, alteration, independent of the differences in ontogenetic, topographic and transmitter producing characteristics of the host neurons as far as they are dopamine-recipient and non-dopaminergic in nature (cf. Lacey et al. 1988).

Acknowledgment: This study was in part supported by Grant (7-A) from National Center of Neurology and Psychiatry (NCNP) of the Ministry of Health and Welfare Japan.

\section{References}

Creese, I. and Iversen, S.D. (1973). Blockade of amphetamine induced motor stimulation and stereotype in the adult rat following neonatal treatment with 6-hydroxydopamine. Brain Res. 55, 369-382.

Higashi, H., Inanaga, K., Nishi, S. and Uchimura, N. (1989). Enhancement of dopamine actions on rat nucleus accumbens neurones in vitro after methamphetamine pre-treatment. J. Physiol. (Lond.) 408, 587-603.

LaCey,M.G., Mercuri, N.B. and North, R.A. (1988). On the potassium conductance increase activated by $\mathrm{GABA}_{2}$ and dopamine $\mathrm{D}_{2}$ receptors in rat substantia nigra neurones. J. Physiol. (Lond.) 401, 437-453.

Uchimura, N., Higashi, H. and Nishi,S. (1986). Hyperpolarizing and depolarizing actions of dopamine via D-1 and D-2 receptors on nu- 
cleus accumbens neurons. Brain Res. 375, (1989). Dopamine receptors on prefrontal 368-372.

neurons. Kurume Med. J. 36, 151-154.

Yano, H., Tanaka, E., Higashi, H. and Nishi, S. 